\title{
THEORETICAL STRENGTH OF SOLIDS
}

The significance of theoretical strength (TS) investigations is explained and a brief overview of the current state of TS calculations is presented on the background of a historical evolution. Influence of crystal defects on TS is outlined by taking into account published theoretical models. The study is completed by a discussion concerning differences between theoretical and experimental results.

\section{Introduction}

The strength of engineering materials is usually controlled by nucleation and motion of dislocations or microcracks. If such defects were not present, the material would only fail if the theoretical (ideal) strength were reached. As a rule, this value is related to the infinite perfect monocrystal (as a generally most stable state of a solid) of particular chemical composition under defined loading mode. Starting from the beginning of the last century, there is a more or less continuous effort expended in order to obtain theoretical and experimental data concerning TS of various solids [1]. The TS values set an upper limit to the envelope of attainable strength and its knowledge enables us to assess the gap remaining to upper strength values of advanced engineering materials in each period of time. However, this is by far not the only reason for the TS investigation.

From the theoretical point of view, the TS plays a decisive role in the fundamental theory of fracture. For example, the stress necessary for nucleation of dislocation loop can be identified with the shear TS value and the local stress for nucleation of a cleavage crack should overcome the tensile TS value $[2,3]$. The ratio of these values expresses the tendency of the crystal matrix to become brittle or ductile [4, 5]. From the practical point of view, the shear TS appears to control both the onset of fracture and dislocation nucleation in defect-free thin films and, in particular, in nanostructured materials that are currently being developed. It has been confirmed most eloquently by nanoindentation experiments (see e. g. [6, 7]). Moreover, the perfect monocrystalline wires (whiskers) are used as reinforcements in advanced composite materials and large metallic and ceramic monocrystals start to be important in special engineering components, e.g. in turbine blades [8].

When considering a perfect crystal deforming homogeneously in a nonlinear elastic way [9], the total internal energy of the crystal can be expanded as

$$
\begin{aligned}
& E=E_{0}+V \sum_{i} \sigma_{i} \eta_{i}+\frac{1}{2} V \sum_{i} \sum_{j} C_{i j} \eta_{i} \eta_{j}+O\left(\eta^{3}\right) \\
& i, j=1,2, \ldots, 6,
\end{aligned}
$$

where $\sigma_{i}$ are components of the stress tensor, $\eta_{i}$ are components of the Lagrangian strain tensor, $C_{i j}$ are the second order elastic coefficients and $V$ is the crystal volume. Here, the simple Voigt notation can be used since the tensors $\sigma_{i j}, \eta_{i j}$ and $C_{i j k l}(i, j, k, l=$ $=1,2,3)$ are symmetric with respect $(i j) \leftrightarrow(j i)$ to interchange. By setting $E_{0}=0$ and using the internal energy per volume unit $E_{u}=E / V$, one can simply write

$$
\begin{aligned}
C_{i j} & =\frac{\partial^{2} E_{u}}{\partial \eta_{i} \partial \eta_{j}} \\
\sigma_{i} & =\frac{\partial E_{u}}{\partial \eta_{i}} .
\end{aligned}
$$

The energy-strain curve can be determined using empirical interatomic potentials or calculating the electronic structure of the crystal. For each particular loading case, the TS is characterized by a set of 6 values of the associated stress tensor components. Consequently, an infinite number of "theoretical strengths" exists for a given crystal. For practical reasons, only special loading cases, determined by a single value of the stress tensor component, used to be connected with the TS value. It concerns the uniaxial and the three-axial (hydrostatic) tension and compression loading modes as well as the simple shear case. The respective TS values denoted as $\sigma_{i u t}, \sigma_{i u c}, \sigma_{i h t}, \sigma_{i h c}$ and $\tau_{i s}$ cover the most important stress state range occurring in engineering practice. In these cases, TS corresponds to a maximum reachable gradient on the energy-strain curve and its attainment is accompanied by a mechanical instability of the crystal lattice.

\section{The History of Theoretical Strength Investigation}

The well known classical estimations of TS values $\tau_{i s}$ and $\sigma_{i u t}$ are those of Frenkel [10] and Orowan-Polanyi [11]:

$$
\begin{aligned}
& \tau_{i s}=\frac{G b}{2 \pi h}, \\
& \sigma_{i u t}=\left(\frac{E \gamma}{a_{0}}\right)^{1 / 2},
\end{aligned}
$$

\footnotetext{
* Jaroslav Pokluda

Institute of Engineering Physics, Brno University of Technology, Technická 2, CZ-616 69 Brno, Czech Republic
} 
where $E$ and $G$ are elastic moduli in tension and shear, $b$ is the size of the Burgers vector, $h$ is the distance between shear planes, $\gamma$ is the surface energy and $a_{0}$ is the lattice constant in the tensile direction. Both expressions can be easily derived assuming the sinusoidal stress-strain curve. In spite of a simple pair atomic interaction approach, both relations give a plausible orientation results $\tau_{i s} \approx G / 10$ and $\sigma_{\text {iut }} \approx E / 10$ for TS values.

The Mackenzie theory [12] represents a further milestone in the development of TS calculations. The first three terms of the Fourier expansion are used as the energy-strain curve. On the other hand, however, it allowed some physically irrelevant assumptions leading to very small values of $\tau_{i s}=G / 30$ for fcc. crystals [13] Since that value seemed to be rather close to some experimental results, an optimistic conclusion was accepted simultaneously with a term change from theoretical to ideal strength $[1,12,14]$. However, more recent semiempirical and ab initio approaches $[13,15]$ confirmed a good validity of the classical result (4). Therefore, we keep use the term "theoretical strength" as a more relevant one.

During the last 30 years, many types of empirical interatomic potentials were proposed as Johnson, Morse, Born-Mayer, LennardJones, Stillinger-Weber, ionic, polynomial, etc. Empirical parameters in these potentials are to be established by fitting to experimental data on equilibrium lattice parameter $a_{0}$, elasticity constants $C_{i j}$ or cohesive energy $U_{0}$. For more extensive historical overview of empirical approaches to TS see, e.g. [1, 14, 16]. In the last 25 years, semiempirical potentials constructed according to either Finnis and Sinclair scheme (FS) [17] or embedded-atom method (EAM) [18] became very popular for modelling extended lattice defects like grain boundary structure in alloys. The FS potential was constructed for many types of binary alloys reproducing exactly the values $a_{0}, c_{i j}, U_{0}$, the vacancy formation energies $U_{v}$ as well as the stacking fault energies $U_{s f}$ [19]. The EAM potentials allow exact fits to elastic moduli of the third order $C_{i j k}$ and yield also reasonable phonon frequency spectra [20].

The values of $a_{0}, C_{i j}$ and $C_{i j k}$ characterise the closest vicinity of the unstressed equilibrium state and the quantities $U_{0}, U_{v}$ and $U_{s f}$ are of integral character. The TS value, however, corresponds typically to the $10-20$ per cent atomic stretch from their equilibrium (unstressed) lattice. Therefore, approaches based on electronic structure calculations - so called ab initio (or first principles) methods - started to appear since 1980 [21]. They deal with approximate solutions of many-particle Schrödinger equation for solid crystal and enable the calculation of the energy-strain curve without any experimental calibration at all. Assumptions like the adiabatic approximation, density functional theory, variation principle and tight-binding approximation are commonly used in the models [22]. The last approximation enables to use various systems of basic functions for the description of one-electron atomic waves. It leads to a number of methods like, e.g., Augmented Plane Wave (APW), Discrete Variational cluster Method (DVM) or Muffin-Tin Orbitals (MTO). Methods based on Green functions, as KoringaKohn-Rostocker, or on various pseudopotentials are also frequently used. Generally, such approaches request advanced computers and a lot of computation time. On the other hand, computational methods as the full potential linear augmented plane waves (FLAPW) or, the less general linear muffin thin orbitals (LMTO), can be successfully applied without extraordinary demands on computer level or time. The FLAPW method is among the most accurate methods for electronic structure calculations. It is a procedure solving the Kohn-Sham equations for the ground-state density, total energy and eigenvalues of many-electron system by introducing the basic functions especially adapted to the problem. The lattice unit cell is divided into the non-overlapping atomic spheres (centred at the atomic sites) and the interstitial region. The potential is expanded in the following form

$$
\begin{array}{ll}
V(r)=\sum_{l m} V_{l m}(r) Y_{l m}(r) & \text { inside sphere } \\
V(r)=\sum_{K} V_{K} e^{i K r} & \text { outside sphere }
\end{array}
$$

where $l, m$ are quantum numbers. Inside the atomic sphere a linear combination of radial functions $V_{l m}(r)$ times spherical harmonics $Y_{l m}$ is used unlike a plane wave expansion in the interstitial region outside spheres. The LMTO approximation of LAPW retains only the $l=m=0$ component inside the sphere (spherical average) and the $K=0$ outside (volume average). This method is particularly useful in solving the high-symmetry problems as, e.g., the hydrostatic loading of cubic.

\section{The State of the Art}

For the present, the ab initio approaches are able to yield a sufficiently precise prediction of the mechanical behaviour far enough from the unstressed equilibrium states. However, they have to be supplemented by an assessment of the mechanical stability of the loaded system.

A general stability condition for a quasi-stationary stressed system leads to the requirement that the free energy (and at $T=0$ also the total internal energy) be minimum in subsequent constant stress ensembles in accordance with the second law of thermodynamics [23-25]. If the solid is infinitesimally strained by $\varepsilon_{i j}$ from a reference state associated with the stress $\sigma_{i j}$ (in the standard notation), the related Cauchy (true) stress $t_{i j}$ can be expressed as

$$
t_{i j}=\sigma_{i j}+B_{i j k l} \varepsilon_{k l},
$$

where

$$
\begin{aligned}
B_{i j k l} & =C_{i j k l}+\frac{1}{2}\left(\delta_{i k} \sigma_{j l}+\delta_{j k} \sigma_{i l}+\delta_{i l} \sigma_{j k}+\right. \\
& \left.+\delta_{j l} \sigma_{i k}+2 \delta_{k l} \sigma_{i j}\right)
\end{aligned}
$$

is the elastic stiffness matrix $(i, j, k . l=1,2,3)$, generally asymmetric towards $(i j) \leftrightarrow(j i)$ interchange. Construction of this matrix is crucial for stability assessment. Namely, the system can be considered to be unstable when it holds

$$
\operatorname{det}|\boldsymbol{B}|=0
$$


for the first time during the loading. It should be emphasized that the elastic moduli in eq. (7) are the local ones, corresponding to each point on the deformation path. Their values should be determined by introducing a sufficient number of independent small deviations (strain increments) from the original deformation path in each of its points. The solution of eq. (8) yields a different number of possible stability conditions for different crystal lattice symmetries as well as different loading modes. The lowest possible number of necessary stability conditions (only two) corresponds to the isotropic solid.

For example, in case of hydrostatic loading of a cubic crystal one can write $C_{11} \neq 0, C_{12} \neq 0, C_{44} \neq 0$, and $C_{i j}=0$, others and the simple relation $\sigma_{i j}=\sigma \delta_{i j}$ holds for the stress tensor. By introducing these relations to eq. (8), one obtains the following stability conditions [23]:

$$
\begin{aligned}
& C_{11}+2 C_{12}-\sigma>0, \\
& C_{11}-C_{12}+2 \sigma>0, \\
& C_{44}+\sigma>0 .
\end{aligned}
$$

The first condition prevents the bulk modulus from vanishing (or getting negative) during the loading. Obviously, the left-hand side differs from the bulk modulus for the stress-free state $\sigma=0$ only by a multiplication constant. The violation of this criterion is directly related to the inflexion point on the energy-strain curve and, therefore, no special tests along the deformation path are needed for its analysis. Conditions (9b) and (9c) are related to the vanishing of shear moduli and need special tests.

In general, two basic cases of instability behaviour related to the TS can be distinguished when analysing the crystal deformation:

i) the instability occurs along the original deformation path,

ii) the instability changes the loading mode or the type of the deformation path.

The first kind of instability means that the process of unstable crystal collapse starts at the point of inflexion on the same (original) deformation path. Assuming the constant stress ensembles (i.e. the stress-controlled loading), the crystal starts to spontaneously disintegrate after reaching this point. During the process, however, strain induced phase transformations (so-called displacive transformations) may appear along the deformation path [26-28]. They are of the first order and, therefore, accompanied by a symmetry-dictated extrema on the stress-strain curve. Consequently, more "TS values" can be found related to different points of inflexion on the energy-strain curve. The TS is determined by the stress associated with the first point of inflexion on the original strainenergy curve. All other inflexion points are preceded by a break down of at least one stability condition.

The second-kind instability occurs before reaching the first point of inflexion on the original energy-strain curve. It changes the type of the deformation path (e.g. the bifurcation from the tetragonal to the trigonal tensile path in the uniaxial tensile test of fcc crystals) or it may simply cause a change in the loading mode (e.g. from the tensile to the shear or vice versa). In that case, the TS corresponds to the stress related to the point of the first break down of a stability condition preceding the point of inflection.

Beside the violation of mechanical stability conditions, some phonon instabilities may be expected along the deformation path [28]. Unfortunately, a too limited number of relevant papers has appeared until now in order to be able to present a more general statement concerning the role of the phonon resonance in the TS analysis. Thus, the currently used methodology for calculating the TS of the particular crystal can be summarised into the following points:

1. Construction of a suitable empirical interatomic potential or calculation of the electronic structure.

2. Calculation of the strain-energy curve and the related stressstrain curve for the specific deformation path.

3. Formulation of stability conditions and calculation of their left-hand side values as functions of strain.

4. Establishment of elastic and phonon instability ranges on the strain-energy and/or stress-strain curve.

5. Determination of TS value as a stress related to the first point of inflexion or to the first instability point on the stress strainenergy curve.

\section{Influence of lattice defects and temperature}

In real perfect crystals (whiskers), a presence of some imperfections is to be expected, at least, the equilibrium concentration of vacancies and a certain level of surface roughness. Thus, it seems to be correct to mention the effects of lattice defects, surface roughness and temperature on TS. From the principal reasons, the strength of imperfect crystals can not be called as TS any more. In this paragraph, therefore, only the term „strength“ will be used instead of TS.

a) Point defects

Vacancies are inevitable in real crystals just near the zero Kelvin temperature. However, the effect of monovacancies on strength is negligible. It can be clearly seen from the fact that the simple formula (5) for $\sigma_{\text {iut }}$ is equal to the Griffith criterion for a nanocrack of the atomic size - a vacancy. The effect of impurities and alloying atoms on strength was studied in several works based on ab initio methods [29-31]. In summary, the influence of a low concentration of point defects on strength seems to be very small.

b) Dislocations

Dislocation slip is possible under shear stresses above the Peierls-Nabbarro stress. The strength might be reduced by 4 orders (or even more) when the P-N stress is as low as in metals,. On the other hand, the P-N stress is extremely high in ceramic covalent crystals $\left(\mathrm{C}, \mathrm{Si}, \mathrm{SiC}, \mathrm{ZnS}, \mathrm{Si}_{3} \mathrm{~N}_{4}\right)$ and complex ionic crystals $\left(\mathrm{MgAl}_{2} \mathrm{O}_{4}, \mathrm{Al}_{2} \mathrm{O}_{3}, \mathrm{Al}_{2} \mathrm{O}_{3} \cdot \mathrm{MgO}\right)$ so that the dislocations are practically sessile at the near zero temperature 
[32]. Therefore, only the tensile strength can be reduced by about tens of percents due to microcracks initiating by the stress relaxation around dislocations with long Burgers vectors.

c) Stacking faults

As far as we know, no special studies on the stacking fault (SF) influence on strength were performed. Atoms on the stable SF plane lie in the local energy minimum and no stress is induced in surrounding volume. The energy of the SF per atom is of about two orders lower than that of the free surface. We may, therefore, deduce that the influence of SFs on the strength value can be neglected.

d) Free surface and notches

The effect of perfectly flat surface on strength can be also considered to be negligible. However, just small imperfections like scratches or dimples act as stress concentrators (notches) Their maximum effect on strength value can be roughly estimated by a factor $1+2(l / \rho)^{1 / 2}$, where $l$ is the notch depth and $\rho$ is the curvature of the notch root $(\rho>0)$ [33]

e) Cracks

According to the Griffith law for perfectly brittle materials, an atomically sharp crack of length $a$ causes the drop in tensile or shear strength values by a factor of $\left(a / a_{0}\right)^{1 / 2}\left(a_{0}\right.$ is the lattice parameter). However, only ceramics, semiconductors and, most probably, Mo and $\mathrm{W}$ can be considered to be intrinsically brittle crystals at zero absolute temperature [4, 5]. In all other metals, the dislocation emission appears before the unstable crack growth. This process increases the effective surface energy and blunts the crack tip. Consequently, the drop in strength must be much less steep than that predicted by Griffith law.

\section{f) Phonons (temperature)}

The strength variation with temperature corresponds, basically, to the problem of the role of phonons in deformation and fracture processes. Although the Frenkel expression (4) suggests simply that the variation should be the same as that of the shear modulus, the eq. (5) brings the complication with the temperature dependence of surface energy. The first approaches predicted the drop in the uniaxial strength within the range of several to tens of percents when changing the temperature from $0 \mathrm{~K}$ to $1000 \mathrm{~K}$, depending on the type of the empirical interatomic potential used (short- or long range). Very recent ab initio studies [34] suggest that some phonon instabilities can be coupled with a violation of some shear stability conditions. In general, one can assume that the temperature change in the relevant elastic modulus might be considered to be an acceptable lower-band first approximation to the strength temperature dependence.

\section{Theoretical and experimental results}

Owing to the long history of TS calculations, a number of theoretical results concerning crystals of pure elements and com- pounds is available in literature. On the other hand, the experimental data are still rather limited owing to problems associated with both the specimen preparation and the experimental arrangement. It holds especially for experiments focused on the shear $\tau_{\text {is }}$ and the three-axial $\sigma_{i h t}$ - in the latter case, there is even a lack of any value. Selected theoretical and experimental TS values for various crystals are presented in Tab. 1 .

There is a three-order difference between the strongest and the weakest crystal. As expected, the highest TS values exhibit a diamond crystal with pure covalent bonds and the lowest ones belong to Van der Waals crystals of inert gases stable only in a low temperature range. It should be emphasized, however, that a great majority of $\sigma_{i u t}$ values corresponds to the inflexion point on the energy-strain curve and the stability analysis was omitted. Those values are most probably overestimated. On the other hand, the stability analysis applied to cubic crystals under hydrostatic tension has revealed that, in most cases, no shear instability appeared before reaching the inflexion point [36]. Therefore, values $\sigma_{i h t}$ obtained by ab initio (LMTO-ASA) method can be considered to be very reasonable estimations of TS. A comparison between $\sigma_{i h t}$ values obtained by ab initio LMTO-ASA/LDA calculation and those obtained by empirical approaches is displayed in Fig. 1 for selected crystals. It is clear that, in most cases, the sinusoidal potential overestimates the TS, whereas the Morse approximation underestimates the TS. Results well comparable with the ab initio calculations can be obtained by means of the polynomial potential. The computed $\tau_{i s}$ values are lowest for fcc crystals. Most experimental data obtained on perfect large monocrystals or even on thin whiskers in uniaxial tension are of an order lower than calculated TS values. It might be dedicated to the dislocation assisted shear instability controlling the final fracture process. The very high Peierls-Nabarro stress in covalent and complex ionic ceramic crystals resists to nucleation and motion of dislocations. For such crystals, indeed, the difference between theory and experiment is relatively low. The probably highest ever reported experimental value $\sigma_{\text {iut }}=40 \mathrm{GPa} \approx E / 20$ corresponds to the $\mathrm{ZnO}$ whisker

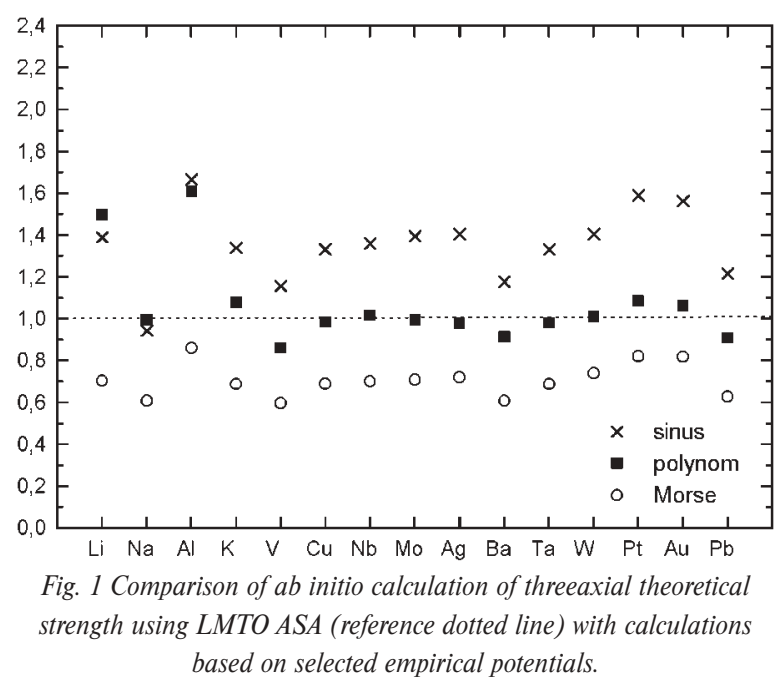


[14]. The gap between the theory and the experiment for metallic crystals becomes much lower by taking the stability conditions into account (e.g. for $\mathrm{Cu}$ crystal [53]), but still remains to be high. This can be understood particularly in terms of various imperfections of experimental procedure, including the crystal defects discussed above. Additionally, there is resonance of short- wave- length phonons and its possible coupling with reaching the shear TS in a significant crystallographic shear system. All such effects are clearly beyond the description supplied by the mechanical stability conditions based on the theoretical continuum mechanics. Let us note, finally, that the currently used ultra-high strength steels exhibit only $\sigma_{\text {iut }} / 10$ value of ultimate strength. From the the-

Calculated and measured values of theoretical strength

Tab. 1.

\begin{tabular}{|c|c|c|c|c|c|c|c|c|c|c|}
\hline \multirow{3}{*}{$\begin{array}{c}\text { Crystal } \\
\mathrm{Na}\end{array}$} & \multirow{3}{*}{$\begin{array}{l}\text { Latt. } \\
\text { bcc }\end{array}$} & \multirow{2}{*}{\multicolumn{2}{|c|}{$\begin{array}{c}\text { Threeaxial } \\
\text { TS [GPa] } \\
\text { theory }\end{array}$}} & \multicolumn{4}{|c|}{$\begin{array}{l}\text { Uniaxial TS } \\
\text { [GPa] }\end{array}$} & \multicolumn{3}{|c|}{$\begin{array}{c}\text { Shear TS } \\
\text { [GPa] }\end{array}$} \\
\hline & & & & \multicolumn{2}{|l|}{ theory } & \multicolumn{2}{|l|}{ experiment } & \multicolumn{2}{|l|}{ theory } & experiment \\
\hline & & $\begin{array}{l}2.0 \mathrm{~A} \\
1.5 \mathrm{~A} \\
1.2 \mathrm{E}\end{array}$ & $\begin{array}{l}{[37]} \\
{[40]} \\
{[16]}\end{array}$ & $\begin{array}{l}0.04<100>\mathrm{E} \\
0.2<110>\mathrm{E} \\
0.9<111>\mathrm{E}\end{array}$ & $\begin{array}{l}{[14]} \\
{[14]} \\
{[14]}\end{array}$ & & & $\begin{array}{l}0.21<111>\mathrm{E} \\
0.20<111>\mathrm{A}\end{array}$ & $\begin{array}{l}{[13]} \\
{[41]}\end{array}$ & \\
\hline $\mathrm{Si}$ & dia & $\begin{array}{l}20.5 \mathrm{~A} \\
25.0 \mathrm{E}\end{array}$ & $\begin{array}{l}{[37]} \\
{[16]}\end{array}$ & $\begin{array}{l}22.4<100>\mathrm{E} \\
47.3<111>\mathrm{E} \\
24.8<111>\mathrm{A}\end{array}$ & $\begin{array}{l}{[14]} \\
{[14]} \\
{[51]}\end{array}$ & $\begin{array}{l}4.14 \\
7.60\end{array}$ & $\begin{array}{l}{[14]} \\
{[14]}\end{array}$ & $\begin{array}{l}13.7<100>\mathrm{E} \\
14.7<110>\mathrm{E}\end{array}$ & $\begin{array}{r}{[1]} \\
{[13]}\end{array}$ & \\
\hline $\mathrm{C}$ & dia & $\begin{array}{l}54.0 \mathrm{~A} \\
138 \mathrm{E}\end{array}$ & $\begin{array}{l}{[39]} \\
{[16]}\end{array}$ & $\begin{array}{l}168<100>\mathrm{E} \\
205<111>\mathrm{E} \\
90<111>\mathrm{A} \\
95<111>\mathrm{A} \\
130<100>\mathrm{A}\end{array}$ & $\begin{array}{l}{[14]} \\
{[14]} \\
{[42]} \\
{[43]} \\
{[42]}\end{array}$ & $\begin{array}{l}\text { 20.7(graph.) } \\
19.6 \text { (graph.) }\end{array}$ & $\begin{array}{r}{[14]} \\
{[1]}\end{array}$ & $131<110>\mathrm{E}$ & [13] & \\
\hline $\mathrm{Cu}$ & fcc & $\begin{array}{l}29.0 \mathrm{~A} \\
19.9 \mathrm{E}\end{array}$ & $\begin{array}{l}{[37]} \\
{[16]}\end{array}$ & $\begin{array}{l}41<100>\mathrm{E} \\
39<111>\mathrm{E} \\
31<110>\mathrm{A} \\
29<111>\mathrm{A} \\
9.3<100>\mathrm{A}\end{array}$ & $\begin{array}{l}{[21]} \\
{[14]} \\
{[44]} \\
{[44]} \\
{[35]}\end{array}$ & $\begin{array}{l}1.25<111> \\
2.94<111> \\
1.50<100> \\
1.74<100> \\
1.59<110>\end{array}$ & $\begin{array}{r}{[1]} \\
{[14]} \\
{[14]} \\
{[14]} \\
{[14]}\end{array}$ & $\begin{array}{l}1.2<112>\mathrm{E} \\
2.9<112>\mathrm{E} \\
4.0<112>\mathrm{A} \\
2.7<112>\mathrm{A}\end{array}$ & $\begin{array}{r}{[1]} \\
{[13]} \\
{[41]} \\
{[41]}\end{array}$ & $0.80<011>$ \\
\hline $\mathrm{Fe}$ & bcc & $\begin{array}{l}42.5 \mathrm{~A} \\
24.1 \mathrm{E} \\
21.5 \mathrm{E}\end{array}$ & $\begin{array}{l}{[36]} \\
{[16]} \\
{[16]}\end{array}$ & $\begin{array}{l}48.0<111>\mathrm{E} \\
30.0<100>\mathrm{E} \\
13<001>\mathrm{A}\end{array}$ & $\begin{array}{l}{[16]} \\
{[16]} \\
{[47]}\end{array}$ & $13.1<111>$ & [1] & $\begin{array}{l}7.3<111>\text { E } \\
6.6<111>\text { E } \\
11.5<111>\text { E }\end{array}$ & $\begin{array}{r}{[14]} \\
{[1]} \\
{[13]} \\
\end{array}$ & $3.56<111>$ \\
\hline $\mathrm{Ti}$ & $\mathrm{bcc}$ & & & $9.5<100>\mathrm{E}$ & [44] & & & & & \\
\hline W & bcc & $\begin{array}{l}53.1 \mathrm{~A} \\
56.8 \mathrm{~A} \\
42.2 \mathrm{E}\end{array}$ & $\begin{array}{l}{[46]} \\
{[37]} \\
{[16]}\end{array}$ & $\begin{array}{l}61<100>\mathrm{E} \\
29.5<100>\mathrm{A} \\
54.3<110>\mathrm{A} \\
40.1<111>\mathrm{A}\end{array}$ & $\begin{array}{l}{[16]} \\
{[49]} \\
{[48]} \\
{[48]}\end{array}$ & $24.7<100>$ & [14] & $\begin{array}{l}18.2<111>\mathrm{E} \\
18.1<111>\mathrm{A}\end{array}$ & $\begin{array}{l}{[14]} \\
{[41]}\end{array}$ & \\
\hline $\mathrm{Pb}$ & $\mathrm{fcc}$ & $\begin{array}{l}8.47 \mathrm{~A} \\
5.47 \mathrm{E}\end{array}$ & $\begin{array}{l}{[39]} \\
{[16]}\end{array}$ & & & & & $0.47<112>\mathrm{E}$ & [13] & \\
\hline $\mathrm{Ar}$ & fcc & $\begin{array}{l}0.25 \mathrm{E} \\
0.15 \mathrm{E}\end{array}$ & $\begin{array}{l}{[14]} \\
{[16]}\end{array}$ & $\begin{array}{l}0.35<100>\mathrm{E} \\
0.35<111>\mathrm{E}\end{array}$ & $\begin{array}{l}{[16]} \\
{[16]}\end{array}$ & & & $\begin{array}{l}0.14<110>\mathrm{E} \\
0.08<112>\mathrm{E}\end{array}$ & $\begin{array}{l}{[13]} \\
{[13]}\end{array}$ & \\
\hline $\mathrm{TiC}$ & B1 & & & $44<001>A$ & [50] & & & & & \\
\hline $\mathrm{NaCl}$ & B1 & $\begin{array}{l}4.3 \mathrm{E} \\
3.4 \mathrm{E}\end{array}$ & $\begin{array}{l}{[14]} \\
{[16]}\end{array}$ & $\begin{array}{l}4.6<111>\mathrm{E} \\
12.4<110>\mathrm{E} \\
4.3<100>\mathrm{E}\end{array}$ & $\begin{array}{l}{[16]} \\
{[14]} \\
{[14]}\end{array}$ & $1.08<100>$ & [14] & $\begin{array}{l}3.2<110>\mathrm{E} \\
2.3<112>\mathrm{E}\end{array}$ & $\begin{array}{l}{[18]} \\
{[14]}\end{array}$ & \\
\hline $\mathrm{MgO}$ & B1 & $8.5 \mathrm{E}$ & [16] & $37<100>\mathrm{E}$ & [16] & 23.7 bend. & [14] & $32.0<110>\mathrm{E}$ & [13] & \\
\hline $\mathrm{Ni}_{3} \mathrm{Al}$ & & $28.1 \mathrm{~A}$ & [35] & $\begin{array}{l}17.5<100>A \\
28<111>A\end{array}$ & $\begin{array}{l}{[52]} \\
{[52]}\end{array}$ & & & & & \\
\hline$\beta-\mathrm{Si}_{3} \mathrm{~N}_{4}$ & P63m & & & $57 \mathrm{E}<100>$ & [17] & $\begin{array}{l}13.5<100> \\
14<100>\end{array}$ & $\begin{array}{r}{[14]} \\
{[1]}\end{array}$ & & & \\
\hline Polyeth. & & & & $26 \mathrm{E}$ & [1] & 3.04 & [14] & & & \\
\hline Kevlar & & & & & & $2.8-3.6$ & [1] & & & \\
\hline
\end{tabular}

A - ab initio, E - Empirical 
oretical point of view, however, materials of an extreme dislocation density could, in principal, achieve the strength level of $\sigma_{\text {iut }} / 2$ [54].

\section{Conclusion}

In the recent time, a significant advance in the solution of theoretical strength problem has been achieved by application of $a b$ initio methods based on electronic structure calculations. A significant success was achieved also by description of extended crystal defects, as grain boundary structures and metastable phases, by means of $a b$ initio supported semi-empirical potentials. From the theoretical point of view, the following items remain to be the main challenges in the near future: $i$ ) ab initio supported semiempirical potentials, ii) extended application and improvement of stability conditions including phonon resonance, iii) the first principle TS studies. In the experimental field, the nanoindentation technique seems to be very promising at least for testing the shear TS. It is also to hope that the technological progress would enable tensile experiments on large perfect crystals by means of (nearly) perfect loading devices. This seems to be even the most crucial point in the future evolution of TS investigations.

\section{Acknowledgement}

This work was done in the framework of the research intention "Advanced functionally graded and nanostructural materials" MSM 262100002 of the Brno University of Technology supported by the Ministry of Education, Youth and Sport of the Czech Republic.

\section{References}

[1] KELLY, A., MACMILLAN, N. H.: Strong Solids. Clarendon Press, Oxford 1986.

[2] JOKL, M. L., VITEK V., MCMAHON JR., C. J.: Acta Metall. 28 (1980), 147.

[3] THOMSON, R.: Sol. State Physics 39 (1986), 1.

[4] POKLUDA, J., ŠANDERA, P.: Phys. Stat. Solidi 167b (1991), 543.

[5] POKLUDA, J., ŠANDERA, P.: Key Engng. Mater. $97-98$ (1994), 467.

[6] BAHR, D. F., KRAMER, D. E., GERBERICH, W. W.: Acta Mater. 46, 3605 (1998).

[7] GOULDSTONE, A., KOH, H. J., ZENG, K. Y., GIANNAKOPOULOS, A. E., SURESH, S.: Acta Mater. 48, 2277 (2000).

[8] GOLDSCHMIDT, D.: In: Materials for Edvanced Power Engineering 1994, Eds. D. Coutsouradis et al. Part I. Dodrecht, Kluwer Academic Publishers 1994, p. 661.

[9] WALLACE, D. C., ED.: Thermodynamics of Crystals. Lohn Willey \& Sons, New York-London-Sydney-Toronto 1972.

[10] FRENKEL, J.: Z. Phys., 37 (1926), 572.

[11] OROWAN, E.: Rep. Progr. Phys., 12 (1949), 185.

[12] KELLY, A.: Strong Solids. Clarendon Press, Oxford 1973.

[13] ŠANDERA, P., POKLUDA, J.: Scr. Met. Mater. 29 (1993), 1445.

[14] MACMILLAN N. H.: In "Atomistics of Fracture." Eds. R.M.Latanision and J.R.Pickens, Plenum Press, New York 1983, p. 95.

[15] PAXTON, A. T., GUMBSCH, P., METHFESSEL, M.: Phil. Mag. Lett. 63 (1991), 267.

[16] ŠANDERA, P., POKLUDA, J.: Kov. Mater. 32 (1994), 180.

[17] FINNIS, M. W., SINCLAIR, J. E.: Phil. Mag. A, 50 (1984), 45.

[18] ADAMS, J. B.. FOILES, S. M.: Phys. Rev. B 41, 3316 (1990).

[19] LUZZI, D. E., YAN, M., ŠOB, M., VITEK, V.: Phys. Rev. Lett. 67, 1894 (1991).

[20] CHANTASIRIWAN, S., MILSTEIN, F.: Phys. Rev. B 67, 14081 (1996).

[21] ESPOSITO, E., CARLSON, A. E., LING, B. D., EHRENREICH, H., GELATT, JR., C. D.: Phil Mag. A41 (1980), 251.

[22] TUREK, I., DRCHAL, V., KUDRNOVSKÝ, J., ŠOB, M., WEINBERGER, P.: Electronic Structure of Disordered Alloys, Surfaces and Interfaces. Kluwer, Boston 1997.

[23] ZHOU, Z., JOÓS, B.: Phys. Rev. B 54, 3841 (1996).

[24] MORRIS, J. W., KRENN, C. R.: Phil. Mag. A 80, 2827 (2000).

[25] YIP, S., LI, J., TANG, M., WANG, J.: Mater. Sci. Eng. A317, 236 (2001).

[26] CRAIEVICH, P. J., WEINERT, M., SANCHEZ, J. M., WATSON, R. E.: Phys. Rev. Lett. 72, 3076 (1994).

[27] ŠOB, M., WANG, L. G., VITEK, V.: Comp. Mat. Sci. 8, 100 (1997).

[28] SHIBUTANI, Y., KRASKO, G. L., ŠOB, M., YIP, S.: Mater. Sci. Res. Int. 5, 225 (1999).

[29] GOODWIN, L., NEEDS, R., HEINE, V.: Phys. Rev. Lett., 60 (1988), 2050.

[30] HUANG, Y. M., SPENCE, J. C. H., SANKEY, O. F.: Phil. Mag., 70 (1994), 53.

[31] SONG, Y., XU, D. S., YANG, R., LI, D., WU, W. T., GUO Z. X.: Mater. Sci. Eng. A260 (1999), 269.

[32] POKLUDA, J., KROUPA, F., OBDRŽÁLEK, L.: Mechanical Properties and Structure of Solids. PC Dir, Brno 1994 (in Czech).

[33] NEUBER, H.: Kerbspannungslehre. Springer Verlag, Berlin 1958.

[34] MA, Y., TSE, J. S., KLUG, D. D.: Phys. Rev. B 67, 140301(R) (2003).

[35] ČERNÝ, M., ŠOB, M., POKLUDA, J., ŠANDERA, P.: In: Proc. ICSMA 13 (submitted). 


\section{KanNiloce}

[36] ČERNÝ, M., POKLUDA, J., ŠANDERA, P., ŠOB, M.: Phys. Rev. B 67, 035116 (2003).

[37] ŠANDERA, P., POKLUDA, J., WANG, L. G., ŠOB, M.: Mater. Sci. Eng. A234-236 (1997), 370.

[38] ClATTERBUCK, D. M., CHRZAN, D. C., MORRIS, JR., J. W.: Phil. Mag. Lett. 82, 141 (2002).

[39] ČERNÝ, M., ŠANDERA, P., POKLUDA, J.: Czech. J. Phys. B49 (1999), 1495.

[40] MILSTEIN, F., RASKY, D. J.: Phys. Rev. B 54, 7016 (1996).

[41] MORRIS JR., J. W., KRENN, D., ROUNDY, D., COHEN, M. L.: In: 2000 Hume-Rothery Symp. in honor of A. G. Khatchaturyan Eds.: Turchi, P. E. and Gonis, A., TMS, Warrendale, PA, 2000 pp. 187-207.

[42] TElling, R. H., PICKARD, C. J., PAINE, M. C., FIELD, J. E.: Phys. Rev. Lett. 84, 5160 (2000).

[43] ROUNDY, D., COHEN, M. L.: Phys. Rev. B 64, 212103 (2001).

[44] ŠOB, M., WANG, L. G., VITEK, V.: Kov. Mater. 36 (1998), 145.

[45] ČERNÝ, M., ŠANDERA, P., POKLUDA, J.: In: Proc. ICSPMA 2003 (to be published).

[46] SON, Y., YANG, R.: Phys. Rev. B59 (1999), 14220.

[47] FRIJÁK, M., ŠOB, M., VITEK, V.: In: Juniormat '01, Institute of Materials Engineering, Brno University of Technology, Brno 2001, pp. 117-120.

[48] ŠOB, M., WANG, L. G., VITEK, V.: Mater. Sci. Eng. A 234-236, 1075 (1997).

[49] ROUNDY, D., KRENN, D., COHEN, M. L., MORRIS JR., J. W.: Phil. Mag. A 81, 1725 (2001).

[50] PRICE, D. L., COOPER, B. R., WILLS, J. M.: Phys. Rev. B 46, 11368 (1992).

[51] VERMA, M. V., VERMA, A., RATHERE, R. P. S.: Acta Phys. Polon. A93 (1998), 479.

[52] ŠOB, M.: In: Proc. ICSMA 13 (to be published).

[53] ČERNÝ, M., ŠOB, M., POKLUDA, J., ŠANDERA, P.: J. Phys. Cond. Matter 16 (2004), 1045.

[54] KROUPA, F.: In: Prediction of Mechanical Properties of Metallic Materials by means of Structural Characteristics. Eds. J. Pokluda and P. Staněk. VÚ070 Brno, 1981, p. 32 (in Czech). 